\title{
Powder milk as a user-friendly tool for baked milk challenge
}

\author{
Sabrine Cherkaoui ${ }^{1}$, Louis Paradis ${ }^{2,3}$, Philippe Bégin ${ }^{2,3}$, Anne Des Roches ${ }^{2 *}$ \\ From Canadian Society of Allergy and Clinical Immunology Annual Scientific Meeting 2013 \\ Toronto, Canada. 3-6 October 2013
}

\section{Background}

Cow's milk allergy is the most common food allergy among children. Previous studies have reported that up to $75 \%$ of children may tolerate baked milk goods. Various forms of baked milk challenges have been used in the literature such as muffins, pizza, and waffles. However, the food used for baked milk challenge is often prepared in a non-standardized manner by the parents at home, raising concerns with regards to validity, reproducibility and convenience. Instant skim milk powder is made by a food process that involves heating skim milk to up to $200^{\circ} \mathrm{C}$ for up to 30 minutes which should be sufficient to denature thermo-labile proteins.

\section{Objective}

To evaluate the usefulness of skim milk powder as a convenient standardized form of baked milk challenge.

\section{Methods}

All challenges to instant skim milk powder (cumulative dose of $4 \mathrm{~g}$ proteins) performed at Sainte-Justine Hospital in Montreal, Canada between November 2008 and January 2013 were retrospectively reviewed. Observed reaction rates to challenge and to subsequent home introduction were compared to previous literature using different forms of baked milk. Demographic data, clinical characteristics, skin prick tests (SPT) and specific IgE levels were compared between those that passed and those that failed the challenge.

\section{Results}

Thirty-nine children underwent an open food challenge to instant skim milk powder and thirty patients $(76,9 \%)$ passed the challenge. All of those who passed the challenge successfully introduced baked milk products at home. Compared to those who were baked milk tolerant, baked milk reactive children had higher median specific IgE levels to cow's milk $(\mathrm{P}<.0005)$, casein $(\mathrm{P}<.001)$, $\alpha$-lactalbumin $(\mathrm{P}<.001)$ and $\beta$-lactoglobulin $(\mathrm{P}<.04)$. Both cohort reaction rates and characteristics were comparable to previous literature using other forms of baked milk product for challenge.

\section{Conclusion}

Challenge with instant skim milk powder is a safe, convenient and easily standardized alternative to home baked food for baked milk challenge.

\section{Authors' details \\ ${ }^{1}$ Division of Internal Medicine, Department of Medicine, University of Montreal, Montreal, QC, Canada. ${ }^{2}$ Divisions of Pediatric Allergy and Immunology, Department of Pediatrics, Sainte-Justine Hospital, Montreal, QC, Canada. ${ }^{3}$ Divison of Clinical Immunology and Allergy, Department of Medicine, University of Montreal, QC, Canada.}

Published: 3 March 2014

doi:10.1186/1710-1492-10-S1-A33

Cite this article as: Cherkaoui et al:: Powder milk as a user-friendly tool for baked milk challenge. Allergy, Asthma \& Clinical Immunology 2014 10(Suppl 1):A33.

\footnotetext{
* Correspondence: a.des.roches@umontreal.ca

${ }^{2}$ Divisions of Pediatric Allergy and Immunology, Department of Pediatrics,

Sainte-Justine Hospital, Montreal, QC, Canada

Full list of author information is available at the end of the article
} 